\title{
La Révolution française. Dynamiques, influences,
} débats. 1787-1804

Hervé Leuwers

\section{Q OpenEdition \\ 1 Journals}

Édition électronique

URL : https://journals.openedition.org/ahrf/2012

DOI : 10.4000/ahrf.2012

ISSN : 1952-403X

Éditeur :

Armand Colin, Société des études robespierristes

Édition imprimée

Date de publication : 1 juin 2005

Pagination : 178-180

ISSN : 0003-4436

Référence électronique

Hervé Leuwers, "La Révolution française. Dynamiques, influences, débats. 1787-1804 », Annales

historiques de la Révolution française [En ligne], 340 | avril-juin 2005, mis en ligne le 20 avril 2006, consulté le 22 avril 2022. URL : http://journals.openedition.org/ahrf/2012 ; DOI : https://doi.org/ 10.4000/ahrf.2012

Ce document a été généré automatiquement le 22 avril 2022.

Tous droits réservés 


\title{
La Révolution française. Dynamiques, influences, débats. 1787-1804
}

\author{
Hervé Leuwers
}

\section{RÉFÉRENCE}

Michel BIARD, Pascal DUPUY, La Révolution française. Dynamiques, influences, débats.

1787-1804, Paris, Armand Colin, 2004, 348 p., ISBN 2-200-26385-6, $30 €$.

1 Paru en parallèle aux études destinées aux candidats au C.A.P.E.S. et à l'agrégation, mais s'inscrivant dans la continuité des manuels qui, d'A. Soboul à M. Vovelle, J.-P. Bertaud, J.-C. Martin ou J.-P. Jessenne, font découvrir la Révolution aux étudiants, l'ouvrage de M. Biard et P. Dupuy entend offrir sur cette période une «nouvelle synthèse » (p. 5) ; parce qu'il se nourrit des publications de ces quinze dernières années, le travail répond pleinement aux objectifs affichés. Dense, riche et exigeant, mais également clairement écrit, il offre au lecteur une synthèse qui fait place à des thématiques longtemps délaissées des manuels (théâtre, colonies, élections...) et aux conclusions des travaux qui ont marqué ces dernières années. Par certains côtés, cette présentation s'enrichit d'un bilan des recherches, sans en éluder les zones d'ombre; en ces occasions, les auteurs rappellent les éléments des débats, tout en défendant leurs positions historiographiques: sur les origines de la Révolution, sur le sens de la Terreur... Le texte invite à des approfondissements que facilitent les "renvois bibliographiques» de fin de chapitre, ainsi qu'une bibliographie générale essentiellement consacrée aux travaux postérieurs à 1989.

2 Fidèle à une ouverture qui a marqué la recherche révolutionnaire, le livre entend replacer l'événement dans son contexte international; l'ambition dépasse l'évocation des seules confrontations militaires pour revenir sur les troubles qui ont marqué l'Europe et l'Amérique du dernier tiers du XVIIIe siècle. L'ouverture choisie n'est 
aucunement destinée à brosser un tableau international des révolutions dont certaines, d'ailleurs, ne sont que brièvement présentées (Liège) ; elle rassemble les matériaux qui permettent de comprendre les événements de France à la lueur des révoltes et révolutions de l'étranger. La démarche permet d'éviter la recherche des « origines » ou des « causes » de la Révolution au sein des seules frontières du royaume, en rappelant les troubles révolutionnaires qui ont précédé ou accompagné l'événement, sans oublier les révolutions anglaises du XVIIe siècle. Pour autant, en exploitant largement les conclusions de J. Nicolas (La rébellion française), les auteurs ne rejettent aucunement les explications nationales ; à l'opposé, ils ne prétendent pas davantage revivifier la notion de "révolution atlantique " qui, affirment-ils, risque de gommer les spécificités des divers mouvements de révolte ou de révolution qui ont marqué les années 1770-1790 (chap. 1). En fait, le choix est celui d'une lecture désenclavée de la Révolution qui souligne la diversité et la complexité des influences réciproques. Le traitement réservé à la Révolution batave est, de ce point de vue, exemplaire. La naissance de cette République sœur (1795) est simultanément mise en relation avec la politique militaire française et avec les événements révolutionnaires qui avaient précédemment touché les Provinces-Unies. Le sous-titre du livre, d'ailleurs, attire l'attention sur ce jeu des «influences», qui est également au cœur des travaux récents sur les États de la péninsule italienne.

3 Cette approche est insérée dans un temps large, qui commence avant 1789 pour se terminer à la fin du Consulat ; l'espace chronologique répond à la volonté d'une lecture des dynamiques politiques, qui ne s'arrête pas à la succession des assemblées révolutionnaires. Le choix se reflète dans la structure des quatre chapitres (chap. 3-6) consacrés aux événements de France, qui sont rythmés par les ruptures majeures de 1789,1792 et 1794-1795. À chaque étape, et particulièrement aux moments clefs que furent les années 1789-1790 ou l'an II, les faits sont insérés dans une trame interprétative qui laisse une large place aux nuances régionales ; ils sont présentés dans leurs rythmes et dynamiques multiples qui aident à comprendre leur complexité. Au sein de cette présentation, le dernier chapitre, consacré aux années 1795-1804, entend dépasser la rupture de 1799 par une large place faite à l'analyse transversale. Alors que, de 1789 à 1794, l'évolution chronologique sert de matrice au texte, ce sont les cohérences d'ensemble qui sont ici soulignées; le parti pris, qui permet de restituer les héritages et transactions qui ont marqué les transformations successives de la Première République depuis l'an III, s'inspire des colloques qui ont réévalué la place du Directoire dans le processus de retour à l'ordre et à la paix, ou réexaminé l'importance politique des courants républicains à la veille et au lendemain du 18 Brumaire; le regard porté sur le Consulat en sort transformé.

4 Logiquement, la première approche retenue par le manuel est politique et revêt les deux grandes dimensions que les historiens lui ont reconnu ces dernières années. Elle est culturelle, indiscutablement; parmi les chapitres qui invitent à s'interroger sur la nature de la Révolution, celui consacré à « Révolution et culture » permet d'évoquer quelques-uns des chantiers les plus novateurs de ces dernières années, du théâtre aux académies, des prénoms révolutionnaires aux symboles, en passant par l'école (p. 197, mais aussi pp. 92-93) ou la gravure - un peu rapidement, sans doute -. L'approche du politique est également sociale, comme le démontre le remarquable chapitre consacré aux luttes rurales, où la chronologie, la géographie et la typologie des mouvements font l'objet d'analyses synthétiques (chap. 8). L'on peut encore souligner qu'en écho aux nombreux travaux sur les colonies et l'esclavage, l'impact colonial de la Révolution est 
intégré à l'étude des répercussions internationales de l'événement (chap. 13). Dans l'ensemble, les perspectives culturelles et sociales se rejoignent dans l'attention portée à la naissance de la démocratie, au cœur de la synthèse ; les chapitres consacrés à la religion, à l'apprentissage de la politique et aux résistances et oppositions offrent, de ce point de vue, des synthèses éclairantes.

5 En bien des points, l'ouvrage remplit la mission qu'il s'était imposé : celle de « consolider » l'essentiel des acquis de la recherche, de les faire passer des articles, des thèses et des ouvrages spécialisés à la synthèse didactique; il rappelle la nécessaire complexité des analyses, souligne l'interdépendance des événements de France et de l'étranger, en même temps qu'il laisse ouvertes les questions en débat. Une chronologie détaillée, quelques cartes et tableaux complètent utilement cette excellente - et stimulante - initiation aux études révolutionnaires. 